\title{
Demographic data for development
}

Population Council

Follow this and additional works at: https://knowledgecommons.popcouncil.org/departments_sbsr-pgy

Part of the Demography, Population, and Ecology Commons, Family, Life Course, and Society Commons, International Public Health Commons, and the Medicine and Health Commons How does access to this work benefit you? Let us know!

\section{Recommended Citation}

"Demographic data for development," Poverty, Gender, and Youth Brief no. 1. New York: Population Council, 2009. 


\section{(1) Population Council}

\section{Demographic data for development}

\section{Introduction}

$\mathrm{D}$ emographic data provide an essential evidence base for the planning and evaluation of development policies. Accessible data function as a public good, benefitting citizens and the political system as a whole. Even though development data are increasingly being collected in developing countries, it is not clear whether they are being used to their fullest potential by the people who need them most-government officials and other policymakers. The Population Council explored this issue through qualitative research in four sub-Saharan African countries: Ethiopia, Ghana, Senegal, and Uganda.

The Demographic Data for Development case studies consisted of semi-structured interviews with more than 100 policymakers, data producers, and consumers (civil society organizations, nongovernmental organizations, and the media, among others). The project explored the current use of data, desired but inaccessible data, and available but unrequested or unused data. The primary focus was on the underutilization of existing data, particularly the factors that limit the collection, use, and sharing of data. The case studies inquired about censuses, national surveys, budgeting, and service-use statistics to determine how policymakers obtain the data they need to develop sound policies.

\section{Demand for Data}

Demand for data occurs at the local, regional, national, and international levels. At all of these levels, the census is

\section{"How can people use data if they don't know that the data exist?"}

especially important because it provides coverage of the entire population; allows for analysis by subgroups within the population; and is geographically reliable, even for small areas and constituencies. Although demand for data is generally viewed as increasing, the increase is coupled with considerable challenges to obtaining useful data at the subnational level and inadequate capacity to make full use of available data.

Global initiatives with established goals, such as the Millennium Development Goals (MDGs), are increasingly putting pressure on developing countries to quantify the outcomes of donor investments. The case studies revealed that the adoption of results-based budgeting by international donors has had a positive influence on demand for data. A government respondent emphasized that statistics have become particularly important in light of the need to monitor progress: "the pressure to report on the MDGs in particular has influenced data priorities and heightened the ... focus on monitoring and evaluation." Although international demand for data has had some benefits, sustainable data systems require strong internal demand. As one researcher noted, "much of the demand . . . is donor driven. Indigenous

In addition to briefs in the Poverty, Gender, and Youth Briefs series, the Poverty, Gender, and Youth program publishes the Promoting Healthy, Safe, and Productive Transitions to Adulthood series, available at www.popcouncil.org/pgy/TA_Briefs_List.html. 
demand remains weak. Up to now, the main reason for collecting data was to satisfy donor demand, rather than for our own planning needs."

\section{Data and Decentralization}

A move toward administrative decentralization in many countries, including all four of those assessed for this study, provides both an opportunity and a challenge for improved data access and use. Effective decentralization requires planning and budgeting at a local level, necessitating the availability of disaggregated data. However, national data, when available, rarely lend themselves to disaggregation at a meaningful level. Adequate access to information means that data have to exist, they have to be easily obtainable, and appropriate skills have to exist or be developed so that data are effectively used locally and nationally.

In theory, decentralization shifts responsibilities to the municipal/district/local levels and reinforces the need for data. In reality, decentralization has proceeded by fits and starts, impeded by lack of capacity at the lower levels of government. Until these levels of government develop their own capacities, the motivation for national authorities to provide local-level data will be minimal.

"Fundamentally, the statistical system should adapt itself to the requirements of the new development (decentralization) framework."

\section{Impediments to Data Access and Demand}

Even when data are available, potential users may be unaware of their existence or their potential use. Study respondents pointed to poor dissemination as one cause of the inadequate use of data. Another common complaint among respondents was that foreigners often have greater access to a country's data than the citizens of the country. As one respondent said, "outsiders get data because they look for them; . . . as a people we are not in the habit of finding and using data." The core concern here is that unlike local researchers, foreign researchers come from bureaucratic and statistical environments in which access to and use of data are commonplace.
"Few people, even journalists, understand what the poverty index means, so instead of saying the poverty index is this or that, they could explain, for example, that one in three Senegalese is poor, or that half of the population cannot afford to eat."

Delays in the collection and release of data are also known to diminish demand for data from policymakers and the media. According to a government official, "timeliness is a serious problem. ... By the time data are collected, analyzed, and findings released, the context may have changed and the data become less useful." However, statistical offices may not be adequately staffed and supported to be able to process, release, and support access to data to the extent that they would like. Timeliness is also a particular concern for members of the media, who work on strict deadlines.

Access to data is further impeded by lack of confidence in the information available, among both producers and users, and the fear among producers that it might be misused. The demand for data is also built on an awareness of their potential value, not just their existence. Great power may be generated by creating an awareness of the potential for data use among policymakers as well as the general public. As one respondent reported, data are "highly mystified in this country, often considered as something which is only for the researchers and highly mathematical people." Once data are demystified, the general public can be empowered to seek information and use it to hold policymakers accountable. This could potentially create an internal pressure for data, which would augment the growing external demand for information and broaden participation in development discussions within and outside government agencies.

Case-study interviewees repeatedly mentioned the insufficient number of skilled individuals who can support data-collection and data-management efforts. In addition to these human resource constraints, technical difficulties arise. Even when useful technology exists, limited resources present a further challenge to the supply of data. Erratic power supplies, 
poor equipment, and unreliable bandwidth were, in particular, reported to impede both access to and supply of data.

\section{Implications of the Case Studies}

The case studies offered a number of insights about ways to increase access to and use of data.

Proactive dissemination of existing data: In many settings, data are not being fully utilized-indeed, their existence may not be widely known. A targeted initiative (focused on the most valuable data sets) could get the data into the hands of users in forms they can understand and apply. This could help to bring data to policymakers and enhance awareness of the value and existence of data. It is important that access avenues be appropriate for the audience and easy to use, since demand may come from those who are not sophisticated analysts and users. Initiatives to present data in user-friendly formats, such as in summary form on paper or electronically, can increase appreciation and use of data.

\section{"Data for development can be likened to money in an economy or blood in the system of a human being."}

\section{Disaggregate data to the most useful levels: Data sets} presented at a high level of aggregation frustrate many potential users. Perhaps the most urgently needed form of disaggregation is geographic: disaggregated data are useful for policymakers at local levels, enabling them to access the evidence base and to cater to the specific needs of their constituencies. Furthermore, disaggregation by sex, age, or other characteristics is also important and may make the difference as to whether or not a potential user finds data relevant.

Present data in other formats: Presentation in the form of maps is another means to improve data use. This will require countries to create digitized files of political and administrative boundaries at a high degree of disaggregation. However, many countries already have the appropriate cartographical technologies, or are in the process of creating the necessary maps. Once this initial investment has been made, the boundary files can permit the display of many types of data in a pictorial manner.

\section{"Indigenous demand is the only sustainable way to ensure better- quality data, access, and use."}

\section{Facilitate communication between producers and con-} sumers: Data producers, analysts, and consumers are not necessarily in close contact with one another. Increased communication among these parties may create a greater sense of the value of collecting and disseminating data. Such contact might also help to foster a community of data users, regardless of where they fall on the continuum of production/use of data.

Establish access to data as a right: Policy-level interventions can set the stage for expectations about data access and use. This is clearly the case in Ghana, where a Right to Information bill recently became law, modeled on similar provisions in India. Of course, as important as establishing access is in setting high expectations for data accessibility, legislation still needs to be accompanied by many other steps (as noted above) to make data functionally available.

\section{Leadership among the donor community is needed:}

Donors increasingly require that data be made available from projects they fund. However, few donors match this requirement with specific financial support for the task. It will be useful for donors to explore ways to ensure effective sharing and use of available data. Donor requirements should be specific so as not to impede the collection of new data when needed. It is much easier to develop data sharing strategies prospectively and build them into the plans for collecting, documenting, and archiving data.

\section{Conclusion}

The case studies of four sub-Saharan African countries have demonstrated a considerable interest in and a growing demand for data, although in these and other countries the link from data to policy can be far from clear. Access to data is limited by usability characteristics of the data, lack of expertise among users, and inadequate systems for making data available.

The challenge of greater access to and demand for data is a social-cultural problem with many technical aspects. The overarching challenge is not technical, however; it is the need for a cultural acceptance of the requirement for evidence- 


\section{"Quality information used by the media is the most effective advocacy tool."}

based policymaking. The technical problems that underlie data sharing and access to and use of data can be solved, but not without the political will to do so. Political will is more likely to be forged through broad engagement with these issues, rather than through the technical efforts of data producers/users alone. The provision of data whets the appetite for more information; and the use of data by policymakers rewards the efforts of those who collect and supply data. Access to information is hindered when the lack of apparently useful data reduces the interest of policymakers in data, and the lack of interest in data in turn marginalizes the data producers. In future, we must take concrete steps to help bridge the divide between data producers and those who ar-or could be-avid users of data in the development and assessment of policies and programs.

\section{Next Phase}

The second phase of the Demographic Data for Development project seeks to advance access to and use of demographic data by intermediaries, specifically journalists. Initially, the second phase will be conducted in Ghana, Namibia, and Senegal.

\section{Donor}

The William and Flora Hewlett Foundation

\section{References and related publications}

Awusabo-Asare, Kofi, Wendy Baldwin, and Sarah Engebretsen. 2009. "Demographic Data for Development: Ghana," final report. New York: Population Council. <http://www.popcouncil.org/pdfs/ PGY_DDD_Ghana.pdf>

Baldwin, Wendy and Judith Diers. 2009. "Demographic Data for Development in Sub-Saharan Africa," Poverty, Gender, and Youth Working Paper No. 13. New York: Population Council. <http://www.popcouncil.org/pdfs/ wp/pgy/013.pdf>

—_. 2009. "Demographic Data for Development: Overview Report." New York: Population Council. <http://www.popcouncil.org/pdfs/PGY_DDD_Overview.pdf>

Kibombo, Richard, Wendy Baldwin, and Sarah Engebretsen. 2009. "Demographic Data for Development: Uganda," final report. New York: Population Council. <http://www.popcouncil.org/pdfs/ PGY_DDD_Uganda.pdf>

Maruru, Rose, Wendy Baldwin, and Sarah Engebretsen. 2009. "Demographic Data for Development: Senegal," final report. New York: Population Council. <http://www.popcouncil.org/pdfs/PGY_DDD_Senegal.pdf>

Mekonnen, Yared, Wendy Baldwin, and Sarah Engebretsen. 2009. "Demographic Data for Development: Ethiopia," final report. New York: Population Council. $<$ <ttp://www.popcouncil.org/pdfs/PGY_DDD_Ethiopia.pdf>

For more information or for copies of other briefs, contact publications@popcouncil.org For additional resources see www.popcouncil.org/pgy

Population Council

One Dag Hammarskjold Plaza

New York, New York 10017 USA

(C) 2009 by The Population Council, Inc. 